\title{
Olsalazine Sodium
}

National Cancer Institute

\section{Source}

National Cancer Institute. Olsalazine Sodium. NCI Thesaurus. Code C66254.

The sodium salt form of olsalazine with anti-inflammatory activity. Olsalazine sodium is bioconverted to 5-aminosalicylic acid (5-ASA) in the colon by colonic bacteria. 5-ASA has anti-inflammatory activity in ulcerative colitis. 